\title{
Complete genome sequence of Syntrophobacter fumaroxidans strain (MPOB')
}

\author{
Caroline M. Plugge ${ }^{1 *}$, Anne M. Henstra ${ }^{1,2}$, Petra Worm ${ }^{1}$, Daan C. Swarts ${ }^{1}$, Astrid H. \\ Paulitsch-Fuchs ${ }^{3}$, Johannes C.M. Scholten ${ }^{4}$, Athanasios Lykidis ${ }^{5}$, Alla L. Lapidus ${ }^{5}$, Eugene \\ Goltsman $^{5}$, Edwin Kim ${ }^{5}$, Erin McDonald ${ }^{2}$, Lars Rohlin², Bryan R. Crable ${ }^{6}$, Robert P. \\ Gunsalus $^{2}$, Alfons J.M. Stams ${ }^{1}$ and Michael J. McInerney ${ }^{6}$ \\ ${ }^{1}$ Laboratory of Microbiology, Wageningen University, Wageningen, Netherlands \\ ${ }^{2}$ Department of Microbiology, Immunology, and Molecular Genetics, University of \\ California, Los Angeles, CA, USA \\ ${ }^{3}$ Wetsus, Centre of Excellence for Sustainable Water Technology, Leeuwarden, Netherlands \\ ${ }^{4}$ Microbiology Group, Pacific Northwest National Laboratory, Richland, WA, USA \\ ${ }^{5}$ Joint Genome Institute, Walnut Creek, CA, USA \\ ${ }^{6}$ Department of Botany and Microbiology, University of Oklahoma, Norman, OK, USA
}

*Corresponding author: Caroline M. Plugge ( caroline.plugge@wur.nl)

Keywords: Anaerobic, Gram-negative, syntrophy, sulfate reducer, mesophile, propionate conversion, host-defense systems, Syntrophobacteraceae, Syntrophobacter fumaroxidans, Methanospirillum hungatei

Syntrophobacter fumaroxidans strain $\mathrm{MPOB}^{\top}$ is the best-studied species of the genus Syntrophobacter. The species is of interest because of its anaerobic syntrophic lifestyle, its involvement in the conversion of propionate to acetate, $\mathrm{H}_{2}$ and $\mathrm{CO}_{2}$ during the overall degradation of organic matter, and its release of products that serve as substrates for other microorganisms. The strain is able to ferment fumarate in pure culture to $\mathrm{CO}_{2}$ and succinate, and is also able to grow as a sulfate reducer with propionate as an electron donor. This is the first complete genome sequence of a member of the genus Syntrophobacter and a member genus in the family Syntrophobacteraceae. Here we describe the features of this organism, together with the complete genome sequence and annotation. The 4,990,251 bp long genome with its 4,098 protein-coding and 81 RNA genes is a part of the Microbial Genome Program (MGP) and the Genomes to Life (GTL) Program project.

\section{Introduction}

Strain MPOB $^{\mathrm{T}}$ (DSM 10017) is the type strain of Syntrophobacter fumaroxidans [1], which is one of the four described species within the genus of Syntrophobacter [2]. The type species of the genus Syntrophobacter is Syntrophobacter wolinii (DSM 2805) [2,3]. Strain $\mathrm{MPOB}^{\mathrm{T}}$ is currently the beststudied species in the genus Syntrophobacter. The genus name derives from the Greek words "syn", together with "troph", one who feeds, and "bacter", rod shaped, referring to a rod-shaped bacterium growing in syntrophic association with hydrogenand formate-scavenging microorganisms [1]. The species epithet derives from the Latin word "fumaricum" pertaining to fumaric acid and the Latin adjective "oxidans", oxidizing, referring to fumarate fermentation.
Strain $\mathrm{MPOB}^{\mathrm{T}}$ was isolated from granular sludge of a mesophilic upflow anaerobic sludge blanket (UASB) reactor, treating waste from a sugar refinery [1].

All currently identified syntrophic propionateoxidizing bacteria are affiliated either with the class Deltaproteobacteria within the phylum Proteobacteria [4], to which Syntrophobacter belongs, or the class Clostridia within the phylum Firmicutes [57]. Many of the Syntrophobacter spp. are able to use sulfate as the electron acceptor for propionate oxidation and some other organic compounds and hydrogen $[4,8]$. In addition, they can grow by fermentation of pyruvate and fumarate. Smithella propionica is phylogenetically related to the genus Syntrophus [9] but lacks the ability to reduce sulfate. It also uses a different pathway to oxidize propionate distinct from that used by Syntrophobacter 
strains, which one that possibly involves a sixcarbon intermediate. It can also grow on crotonate in pure culture $[9,10]$.

Here we describe the features of Syntrophobacter fumaroxidans strain $\mathrm{MPOB}^{\mathrm{T}}$ together with the complete genome sequence and annotation.

\section{Classification and features}

Cells of $S$. fumaroxidans strain $\mathrm{MPOB}^{\mathrm{T}}$ are short rods with rounded ends of 1.1-1.6 $\times 1.8-2.5 \mu \mathrm{m}$ (Figure 1 and Table 1). Cells are Gram-negative, non-motile, and do not form endospores. The metabolism is strictly anaerobic and can be respiratory or fermentative $[2,4]$. The temperature range for growth is $20-40^{\circ} \mathrm{C}$ (optimum at $37^{\circ} \mathrm{C}$ ).

Strain $\mathrm{MPOB}^{\mathrm{T}}$ utilizes propionate syntrophically via the methylmalonyl-CoA pathway in co-culture with the hydrogen and formate-utilizing methanogen, M. hungatei, and in pure culture using sulfate or fumarate as an electron acceptor [21,22]. In these cases, propionate is converted stoichiometrically to acetate and $\mathrm{CO}_{2}$ with concomitant production of methane, sulfide or succinate, respectively $[1,22]$. Thiosulfate also serves as an electron acceptor, but nitrate is not utilized. Strain MPOB $^{\mathrm{T}}$ ferments fumarate to succinate and $\mathrm{CO}_{2}$ using the acetyl-CoA cleavage pathway [22], and reduces fumarate to succinate with hydrogen or formate as the electron donor $[21,23]$.
Figure 2 shows the phylogenetic neighborhood of $S$. fumaroxidans strain $\mathrm{MPOB}^{\mathrm{T}}$ in a $16 \mathrm{~S}$ rRNA genebased tree. This tree shows that these Gramnegative syntrophic propionate oxidizers form one cluster within the family of Syntrophobacteraceae of the order Syntrophobacterales. All propionate-degrading bacteria from the order Syntrophobacterales are capable of propionate degradation in syntrophic coculture with a syntrophic partner but also as a pure culture coupled to dissimilatory sulfate reduction [8]. The physiological and genomic data on microorganisms capable of syntrophy from the Syntrophobacterales, which are abundantly present in methanogenic environments [25-28], indicate that all have retained their sulfate-reducing capability $[22,29,30]$. Syntrophobacterales contains sulfate-reducing species that are capable of syntrophy, and growth by sulfate reduction, as well as species capable of syntrophy that contain the bisulfite reductase genes $(d s r A B)$, but are not capable of reducing sulfate; indicating an evolutionary connection between the sulfate-reducing and syntrophic lifestyles [8].

The syntrophic species in the Syntrophobacterales can be divided in two groups based on their ability to reduce sulfate or not, which suggests an evolutionary connection between the sulfate-reducing and syntrophic lifestyles [8].

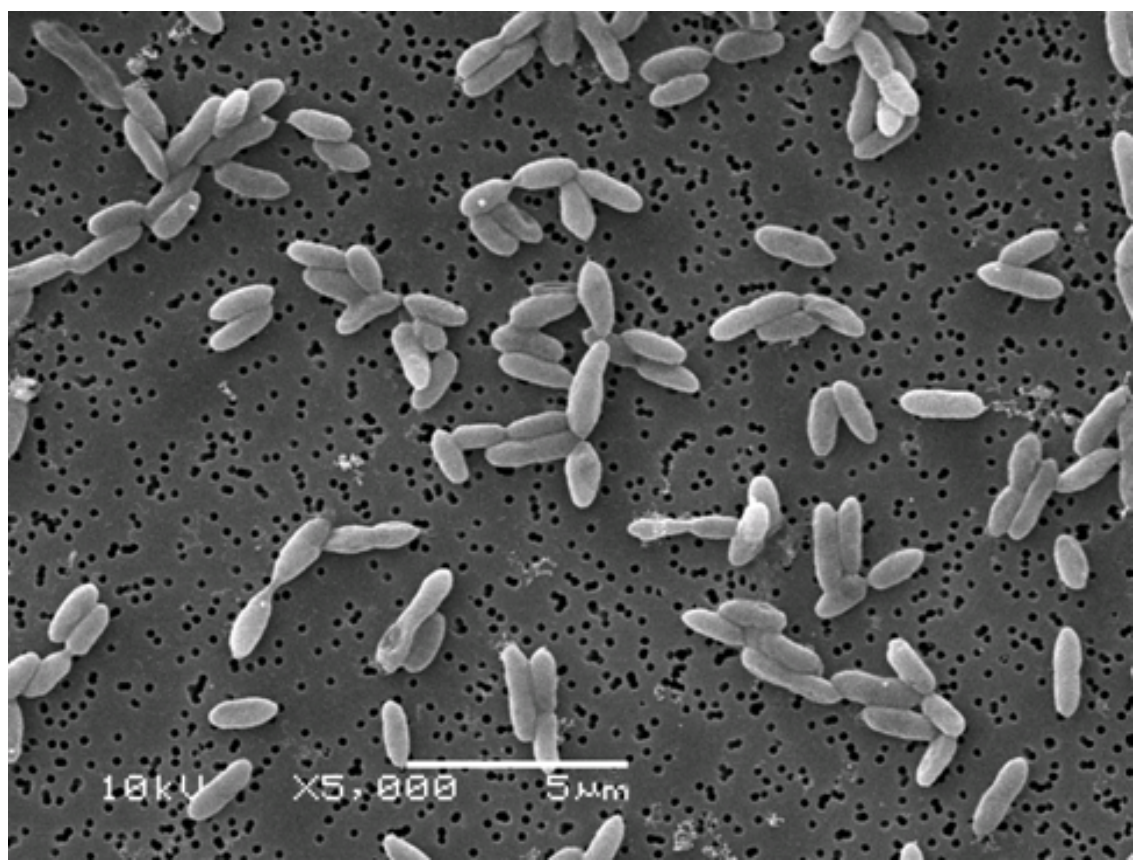

Figure 1. Scanning electron micrograph of $S$. fumaroxidans during exponential phase of growth. 
Table 1. Classification and general features of $S$. fumaroxidans $\mathrm{MPOB}^{\top}$ according to the MIGS recommendations [11].

\begin{tabular}{|c|c|c|c|}
\hline MIGS ID & Property & Term & Evidence code \\
\hline & & Domain Bacteria & TAS [12] \\
\hline & & Phylum Proteobacteria & TAS [13] \\
\hline & & Class Deltaproteobacteria & TAS $[14,15]$ \\
\hline & Current classification & Order Syntrophobacterales & TAS $[14,16]$ \\
\hline & & Family Syntrophobacteraceae & TAS $[14,17]$ \\
\hline & & Genus Syntrophobacter & TAS $[3,18,19]$ \\
\hline & & Species Syntrophobacter fumaroxidans & TAS [1] \\
\hline & & Type strain MPOB & TAS $[1,2]$ \\
\hline & Gram stain & Negative & TAS [1] \\
\hline & Cell shape & rod-shaped & TAS [1] \\
\hline & Motility & non-motile & TAS [1] \\
\hline & Sporulation & non-sporulating & TAS [1] \\
\hline & Temperature range & Mesophilic, $20-40^{\circ} \mathrm{C}$ & TAS [1] \\
\hline & Optimum temperature & $37^{\circ} \mathrm{C}$ & TAS [1] \\
\hline \multirow[t]{3}{*}{ MIGS-22 } & Oxygen requirement & strictly anaerobic & TAS [1] \\
\hline & Carbon source & $\begin{array}{l}\text { In pure culture: fumarate, malate, aspartate and pyruvate, } \\
\text { fumarate }+ \text { propionate, } \mathrm{H}_{2}+\text { fumarate, formate }+ \text { fumarate } \\
\text { fumarate }+ \text { sulfate, } \mathrm{H}_{2}+\text { sulfate, formate }+ \text { sulfate } \\
\text { In syntrophy with hydrogen and formate scavenger, } \\
\text { propionate }\end{array}$ & TAS [1] \\
\hline & Energy source & $\begin{array}{l}\text { Propionate, fumarate, malate, aspartate, pyruvate, } \\
\text { hydrogen, formate }\end{array}$ & TAS [1] \\
\hline MIGS-6 & Habitat & Fresh water sediments, Anaerobic bioreactors & {$[1,4]$} \\
\hline MIGS-15 & Biotic relationship & Free-living & NAS \\
\hline \multirow[t]{3}{*}{ MIGS-14 } & Pathogenicity & Not reported & NAS \\
\hline & Biosafety level & Not reported & NAS \\
\hline & Isolation & $\begin{array}{l}\text { Granular sludge from a mesophilic upflow anaerobic } \\
\text { sludge blanket UASB) reactor treating sugar refinery waste }\end{array}$ & TAS [1] \\
\hline MIGS-4 & Geographic location & Breda, the Netherlands & TAS [1] \\
\hline MIGS-5 & Sample collection time & 1987 & IDA \\
\hline MIGS-4.1 & Latitude & $51^{\circ} 3547.55 \square \quad \mathrm{N}$ & IDA \\
\hline MIGS-4.2 & Longitude & 4 4 $46 \square 12.11$ 回 & IDA \\
\hline MIGS-4.3 & Depth & not reported & NAS \\
\hline MIGS-4.4 & Altitude & not reported & NAS \\
\hline
\end{tabular}

Evidence codes - IDA: Inferred from Direct Assay (first time in publication); TAS: Traceable Author Statement (i.e., a direct report exists in the literature); NAS: Non-traceable Author Statement (i.e., not directly observed for the living, isolated sample, but based on a generally accepted property for the species, or anecdotal evidence). These evidence codes are from the Gene Ontology project [20]. If the evidence code is IDA, then the property was directly observed for a live isolate by one of the authors or an expert mentioned in the acknowledgements. 


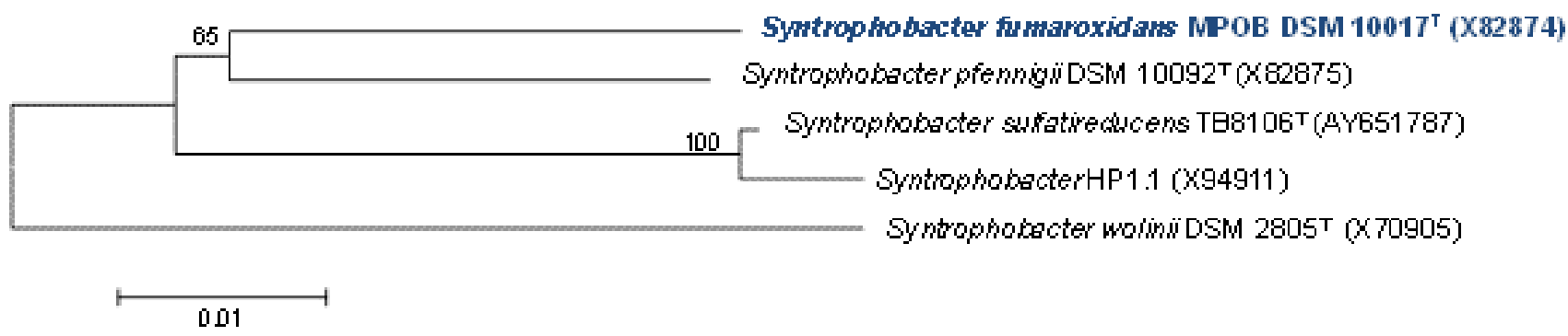

Figure 2. Neighbor-joining tree, based on $16 \mathrm{~S}$ rRNA gene sequences, highlighting the position of Syntrophobacter fumaroxidans strain MPOB DSM $10017^{\top}$ relative to other Syntrophobacter species. Numbers above branches are support values from 1,000 bootstrap replicates if larger than $60 \%$. Strain MPOB, with a genome-sequencing project registered in GOLD [24] printed in blue. Bar indicates 0.01 substitutions per nucleotide position.

Two 16S rRNA gene sequences are present in the genome of strain $\mathrm{MPOB}^{\mathrm{T}}$. Sequence analysis indicates that these two genes are almost identical $(2$ bp difference), and that both genes differ by up to 8 nucleotides from the previously published $16 \mathrm{~S}$ rRNA gene sequence (X82874).

\section{Chemotaxonomy}

S. fumaroxidans strain MPOBT contains $c$ - and $b$ type of cytochromes and the menaquinones MK-6 and MK-7 [1].

\section{Genome sequencing and annotation Genome project history}

This organism was selected for sequencing on the basis of its syntrophic and sulfate-reducing lifestyles and its phylogenetic position, and is part of the Microbial Genome Program (MGP) and the Genomes to Life (GTL) Program. The genome project is deposited in the Genomes OnLine Database [Gc00453] and the complete genome sequence (CP000478) is deposited in GenBank. Sequencing, finishing and annotation were performed by the DOE Joint Genome Institute (JGI). A summary of the project information is shown in Table 2.

Table 2 Genome sequencing project information

\begin{tabular}{|c|c|c|}
\hline MIGS ID & Property & Term \\
\hline MIGS-31 & Finishing quality & Finished \\
\hline MIGS-28 & Libraries used & $3 \mathrm{~kb}$ (pUC18c), 8kb (pMCL200) and 40kb (pcc1Fos) \\
\hline MIGS-29 & Sequencing platforms & Sanger \\
\hline MIGS-31.2 & Sequencing coverage & $7 \times$ \\
\hline MIGS-20 & Assemblers & PGA \\
\hline \multirow[t]{6}{*}{ MIGS-32 } & Gene calling method & Prodigal, GenePRIMP \\
\hline & INSDC / Genbank ID & СР000478 \\
\hline & Genbank Date of Release & October 27, 2006 \\
\hline & GOLD ID & Gc00453 \\
\hline & NCBI project ID & 13013 \\
\hline & Database: IMG & {$[31]$} \\
\hline \multirow{2}{*}{ MIGS -13 } & Source material identifier & DSM 10017 \\
\hline & Project relevance & $\begin{array}{l}\text { Genomes to Life: Bioreactors, Biotechnology, Carbon cycle, } \\
\text { Energy production, Hydrogen production }\end{array}$ \\
\hline
\end{tabular}




\section{Growth conditions and DNA isolation}

$S$. fumaroxidans $\mathrm{MPOB}^{\mathrm{T}}$ was grown at $37^{\circ} \mathrm{C}$ in anaerobic bicarbonate buffered mineral salts medium as was described previously [23]. High molecular weight genomic DNA was isolated from 2 -2.5 g concentrated cell pellets using the CTAB method recommended by Joint Genome Institute (JGI), which can be found at the JGI website [32].

\section{Genome sequencing and assembly}

Syntrophobacter fumaroxidans genomic DNA was sequenced at JGI using a combination of $3 \mathrm{~kb}, 8 \mathrm{~kb}$ and $40 \mathrm{~kb}$ DNA libraries. All general aspects of library construction and sequencing performed at the JGI can be found at the JGI website [32]. The Phred/Phrap/Consed software package [33] was used to assemble all three libraries and to assess quality [34-36]. Possible misassemblies were corrected, and gaps between contigs were closed by editing in Consed, custom primer walks or PCR amplification (Roche Applied Science, Indianapolis, IN). The error rate of the completed genome sequence of $S$. fumaroxidans is less than 1 in 50,000. Pair-wise graphical alignments of whole genome assemblies (e.g. synteny plots) were generated by using the MUMmer system $[37,38]$.

\section{Genome annotation}

Automated gene prediction was performed by using the output of Critica [39] complemented with the output of the Generation and Glimmer models [37]. The predicted CDSs were translated and used to search the National Center for Biotechnology Information (NCBI) nonredundant database, UniProt, TIGRFam, Pfam, PRIAM, KEGG, COG, and InterPro databases. Additional gene prediction analysis and functional annotation was performed within the Integrated Microbial Genomes-Expert Review platform [40].

\section{Genome properties}

The genome is 4,990,251 bp long and contains one circular chromosome with a $59.95 \%$ GC content (Figure 3). Of the 4,179 genes predicted, 4,098 were protein coding genes, 81 RNAs and 34 pseudogenes. A total of $67.2 \%$ of the genes were assigned a putative function while the remaining ones were annotated as hypothetical proteins. The properties and the statistics of the genome are summarized in Table 3. The distribution of genes into COGs functional categories is presented in Table 4.

Table 3 Genome Statistics

\begin{tabular}{lrr}
\hline Attribute & Value & \% of Total \\
\hline Genome size (bp) & $4,990,251$ & 100 \\
DNA coding region (bp) & $4,115,129$ & 82.46 \\
DNA G+C content (bp) & $2,991,592$ & 59.95 \\
Number of replicons & 1 & \\
Extrachromosomal elements & 0 & \\
Total genes & 4,179 & 100 \\
RNA genes & 81 & 1.94 \\
rRNA operons & 6 & 0.14 \\
Protein-coding genes & 4,098 & 98.06 \\
Pseudo genes & 34 & 0.81 \\
Genes with function prediction & 1,289 & 30.85 \\
Genes in paralog clusters & 791 & 18.93 \\
Genes assigned to COGs & 2,959 & 70.81 \\
Genes assigned Pfam domains & 3,075 & 73.58 \\
Genes with signal peptides & 741 & 17.73 \\
Genes with transmembrane helices & 1,035 & 24.77 \\
CRISPR repeats & 4 & \\
\hline
\end{tabular}


Table 4. Number of genes associated with the general COG functional categories

\begin{tabular}{|c|c|c|c|}
\hline Code & Value & $\%$ age & Description \\
\hline$J$ & 170 & 5.18 & Translation, ribosomal structure and biogenesis \\
\hline A & 1 & 0.03 & RNA processing and modification \\
\hline K & 153 & 4.66 & Transcription \\
\hline $\mathrm{L}$ & 139 & 4.24 & Replication, recombination and repair \\
\hline B & 4 & 0.12 & Chromatin structure and dynamics \\
\hline $\mathrm{D}$ & 32 & 0.98 & Cell cycle control, cell division, chromosome partitioning \\
\hline $\mathrm{Y}$ & 0 & 0.00 & Nuclear structure \\
\hline $\mathrm{V}$ & 54 & 1.65 & Defense mechanisms \\
\hline $\mathrm{T}$ & 263 & 8.02 & Signal transduction mechanisms \\
\hline M & 229 & 6.98 & Cell wall/membrane/envelope biogenesis \\
\hline $\mathrm{N}$ & 35 & 1.07 & Cell motility \\
\hline Z & 0 & 0.00 & Cytoskeleton \\
\hline W & 0 & 0.00 & Extracellular structures \\
\hline$U$ & 89 & 2.71 & Intracellular trafficking, secretion, and vesicular transport \\
\hline $\mathrm{O}$ & 145 & 4.42 & Posttranslational modification, protein turnover, chaperones \\
\hline $\mathrm{C}$ & 375 & 11.43 & Energy production and conversion \\
\hline G & 137 & 4.18 & Carbohydrate transport and metabolism \\
\hline $\mathrm{E}$ & 274 & 8.35 & Amino acid transport and metabolism \\
\hline $\mathrm{F}$ & 67 & 2.04 & Nucleotide transport and metabolism \\
\hline $\mathrm{H}$ & 178 & 5.43 & Coenzyme transport and metabolism \\
\hline I & 95 & 2.90 & Lipid transport and metabolism \\
\hline $\mathrm{P}$ & 156 & 4.75 & Inorganic ion transport and metabolism \\
\hline Q & 47 & 1.43 & Secondary metabolites biosynthesis, transport and catabolism \\
\hline $\mathrm{R}$ & 407 & 12.40 & General function prediction only \\
\hline $\mathrm{S}$ & 231 & 7.04 & Function unknown \\
\hline- & 1220 & 29.19 & Not in COGs \\
\hline
\end{tabular}




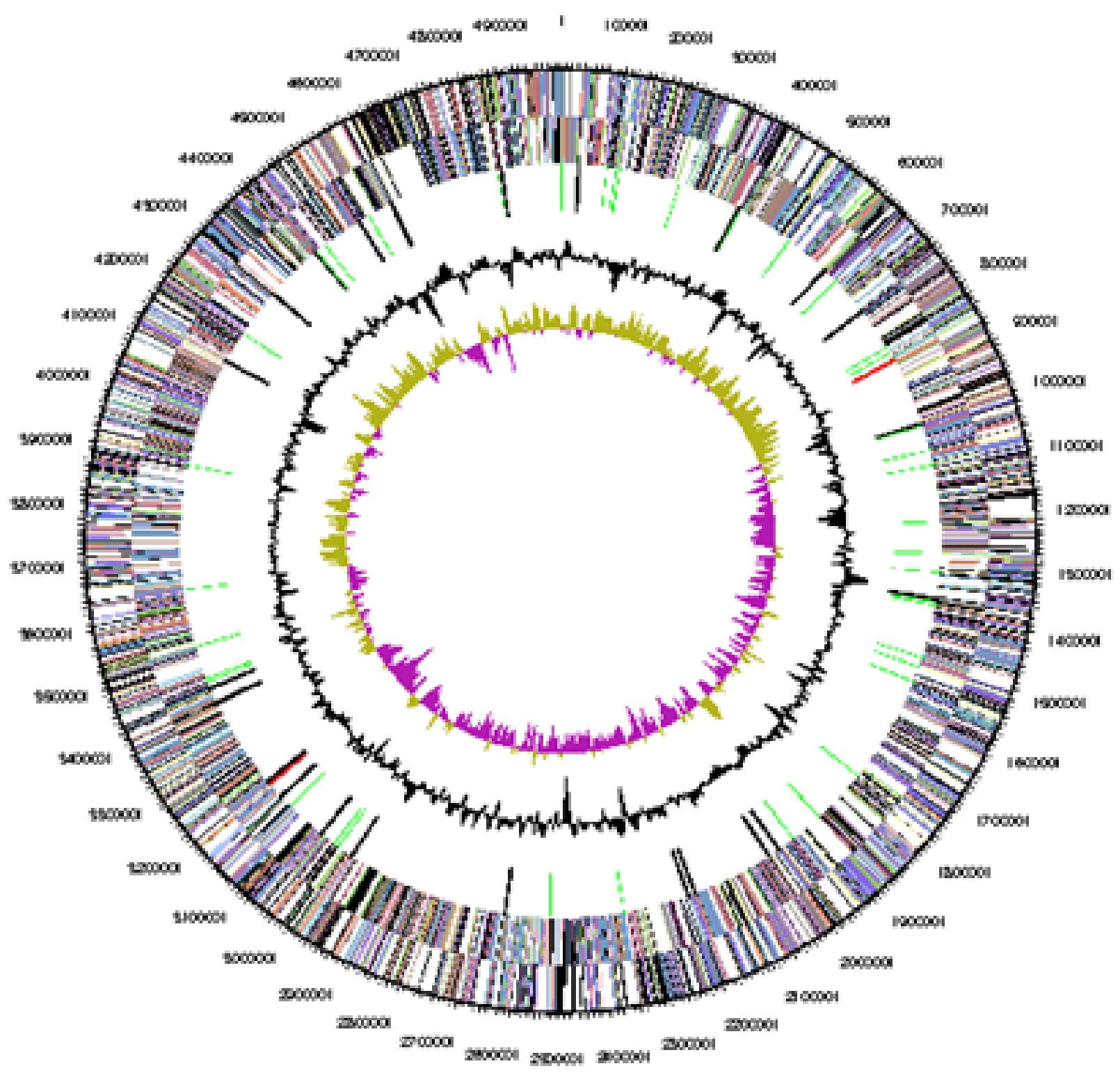

Figure 3. Graphical circular map of the genome. From outside to the center: Genes on for-ward strand (color by COG categories), Genes on reverse strand (color by COG categories), RNA genes (tRNAs green, rRNAs red, other RNAs black), GC content, GC skew.

\section{Comparison to other genomes}

The $S$. fumaroxidans genome is intermediate in size for the Deltaproteobacteria genomes sequenced thus far, which range in size from 1.72 to $13.03 \mathrm{Mbp}$. Notably, it has $1.8 \mathrm{Mbp}$ more DNA than the other well studied syntrophic fatty acid degrader, Syntrophus aciditrophicus SB (3.1 Mbp). When $S$. fumaroxidans ORFs were compared on a pair-wise basis to individual microbial genomes, the best reciprocal BLAST hits revealed the closest associations to the following Deltaproteobacteria: Desulfobacterium autotrophicum HRM2 (1593 reciprocal gene hits), Desulfatibacillum alkenivorans AK-01 (1551), and Desulfovibrio magneticus RS-1 (1448) (Figure 4). Approximately 1,200 genes are similar, and are well conserved across the 25 Gram-negative species shown. The remaining genes (ca. 2,400) represent a novel complement within the $S$. fumaroxidans genome. Notably, Pelobacter propionicus SSM 2379 was the $18^{\text {th }}$ closest to $S$. fumaroxidans. Although $P$. propionicus is not known to grow syntrophically, other Pelobacter species oxidize various alcohols syntrophically [4]. 
In another comparison, the best BLAST hit to any microbial gene was determined (Figure 5) and showed only 306, 209, and 186 closest hits to the genomes of $D$. alkenivorans AK-01, S. aciditrophicus SB, and Desulfarculus baarsii DSM 2075, respectively. Interestingly, no archaeal genomes were identified that suggest the possibility of lateral gene transfer events from these potential syntrophic partners. However, a recent study using an experimental approach and a different bioinformatic platform, the STRING database, which includes known and predicted protein-protein interactions [41,42], discovered that a gene set present in syntrophic bacteria such as Pelobacter carbinolicus, $S$. fumaroxidans, Syntrophomonas wolfei, and Syntrophus aciditrophicus, tended to be clustered with their homologues in archaeal genera, and they were rooted on archaeal species in the constructed phylogenetic trees. This suggests that they were horizontally transferred from archaeal methanogens [43]. Gene products for this gene set are hypothetical.

\section{Carbon flow and electron transfer}

The genome of $S$. fumaroxidans contains genes predicted to encode enzymes that are necessary for the conversion of propionate to acetate and carbon dioxide by the methylmalonyl-CoA pathway (Figure 6). Propionyl-CoA:acetate HSCoA transferase (Sfum_3933) is present as part of a gene cluster encoding several presumably redox active proteins. Two genes annotated as electron transfer flavoprotein (ETF) alpha subunits (Sfum_3928-29) and a gene annotated as an ETF beta subunit (Sfum_3930) are part of this gene cluster, as are genes for a putative hydroxylase (Sfum_3932) and an acyl-CoA dehydrogenase (Sfum_3931). Additionally, a gene annotated as an FAD-dependent oxidoreductase (Sfum_3927) and one encoding a $4 \mathrm{Fe}-4 \mathrm{~S}$ ferredoxin-binding domain (Sfum_3926) are part of this gene cluster. Genes predicted to encode a sigma 54-dependent transcriptional regulator (Sfum_3934) and a protein belonging to the major facilitator superfamily (MFS) flank this gene cluster upstream and downstream, respectively.

Propionyl-CoA is converted first to (S)-methylmalonyl-CoA and then to (R)-methylmalonyl-CoA by methylmalonyl-CoA epimerase (Sfum_0455), which is part of a two-gene cluster and pairs with a gene predicted to code for an ATP-dependent amino acid transport protein (Sfum_0456). This gene cluster appears immediately downstream of a two- gene cluster predicted to encode methylmalonylCoA mutase (Sfum_0457-8). Sfum_1223 may encode a carboxyltransferase involved in cycling carbon dioxide between the decarboxylation of oxaloacetate and the carboxylation of propionyl-CoA to form methylmalonyl-CoA. Methylmalonyl-CoA mutase (Sfum_0457-8) then converts methylmalonyl-CoA to succinyl-CoA. Removal of the CoA group is presumably accomplished by a succinyl-CoA synthetase (Sfum_1702-03), which forms succinate coupled to ATP formation from ADP and phosphate.

Succinate is then further oxidized to fumarate by a membrane-bound succinate dehydrogenase/fumarate reductase. Succinate oxidation via a menaquinone to fumarate is the most energy dependent reaction in the methyl-malonyl-CoA pathway propionate degradation to acetate in $S$. fumaroxidans. Succinate oxidation via menaquinone is endergonic since the midpoint potential of succinate is more positive $(+30 \mathrm{mV})$ than the menaquinone $(-80 \mathrm{mV})$. Therefore, the reaction requires a transmembrane proton gradient to function. Schink [44] calculated that about 0.66 ATP has to be invested to make this reaction energetically possible at a hydrogen partial pressure of $1 \mathrm{~Pa}$ and formate concentrations of $10 \mu \mathrm{M}$, which can be maintained by methanogens in a syntrophic community. The genome of $S$. fumaroxidans contains four gene clusters sdhABC (Sfum_1998-2000), frdABEF (Sfum_4092-4095), sdhAB-1 (Sfum_01720174) and sdhAB-2 (Sfum_2103-2104) with sequence similarity to succinate dehydrogenases or fumarate reductase. S. fumaroxidans might use separate enzymes for succinate oxidation and fumarate reduction. During growth with propionate plus fumarate, $S$. fumaroxidans needs an active fumarate reductase, whereas during growth with propionate plus sulfate, or during syntrophic growth on propionate an active succinate dehydrogenase is required [21].

In $S$. fumaroxidans, the gene cluster sdhABC (Sfum_1998-2000) codes for two cytoplasmic subunits (sdhA and $B$ ) and a five-trans-membrane (5TM) subunit containing heme $(s d h C)$ which is similar to the type B trans-membrane subunit of Wolinella succinogenes Frd and Bacillus subtilis Sdh (Hägerhäll 1997). SdhA contains the conserved catalytic core residues and $\mathrm{SdhB}$ contains motifs for binding of three iron sulfur clusters, [2Fe2S], [4Fe4S], and [3Fe4S]. 


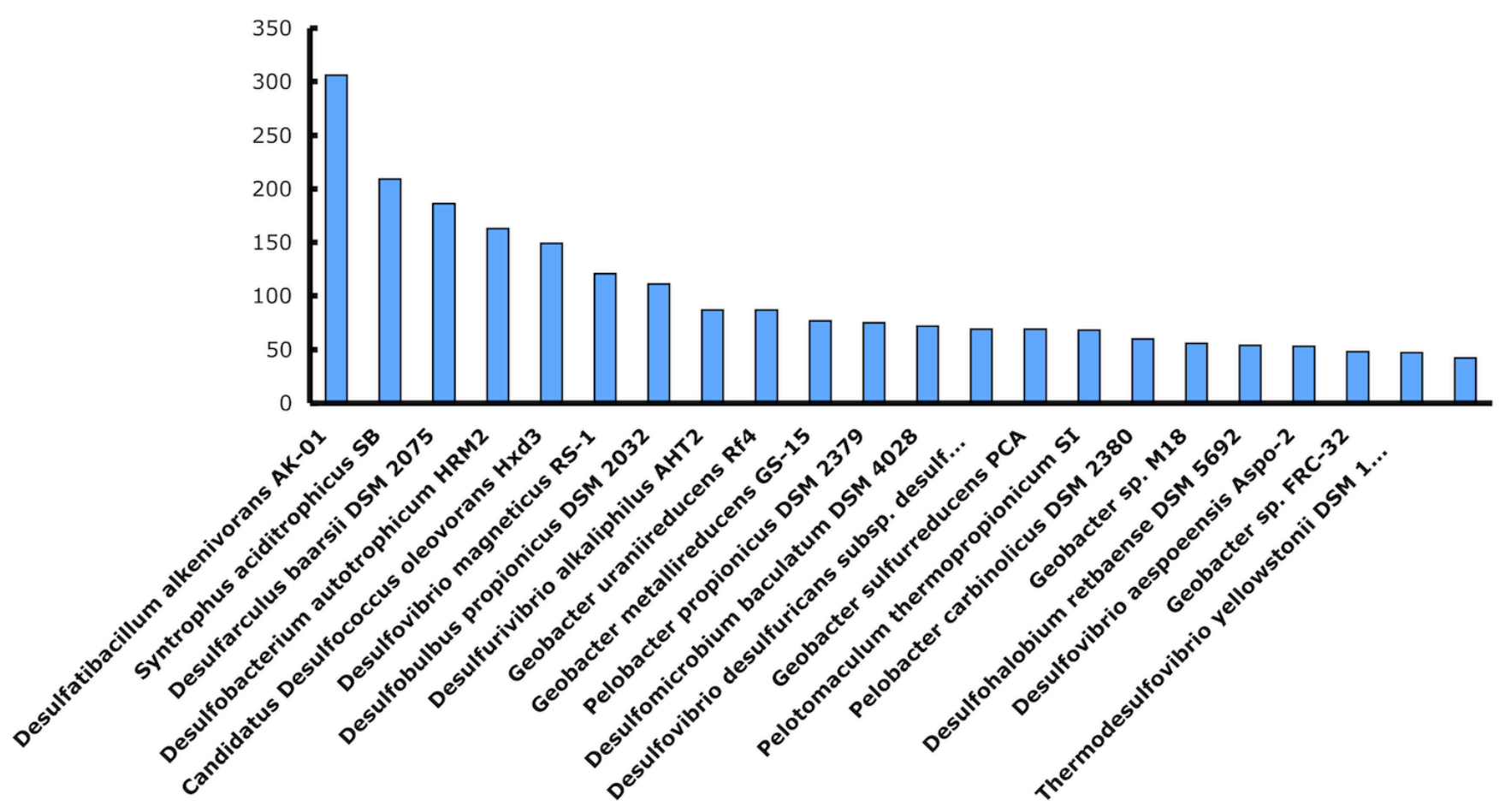

Figure 4. Best reciprocal protein hits for S. fumaroxidans ORFs with other genomes.
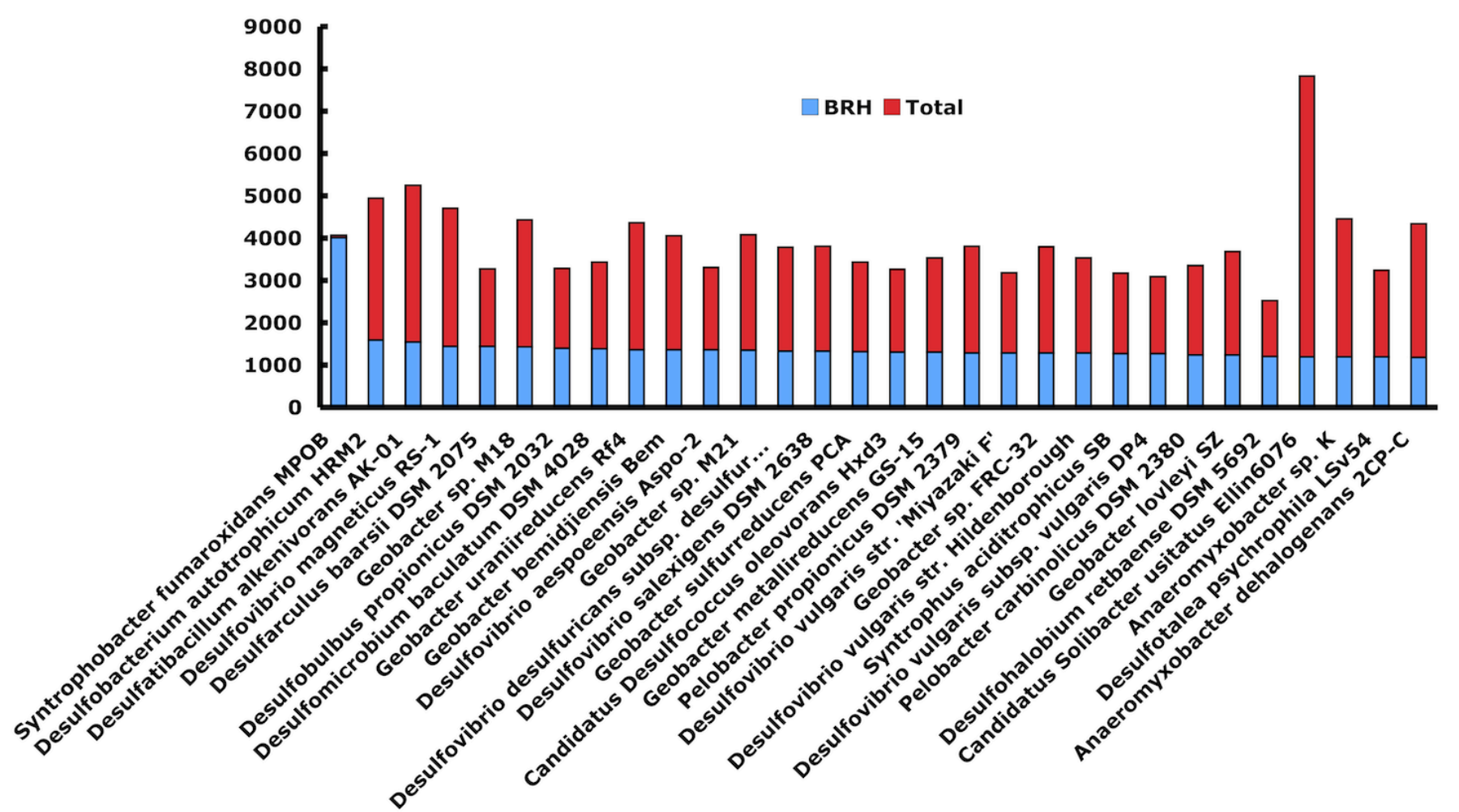

Figure 5. Best Blast hit distribution of $S$. fumaroxidans ORFs with other genomes. In blue: the best reciprocal hits; in red: the total coding DNA sequences (CDS)Insights into the genome. 
The gene cluster frdABEF (Sfum_4092 - 4095) of $S$. fumaroxidans lacks a gene coding for the transmembrane subunit and is therefore classified as a type E Frd [45]. The type E succinate:quinone oxidoreductases differ from the other four types in that they do not contain heme and have two hydrophobic subunits, SdhE and SdhF. Rather, the type E succinate:quinone oxidoreductases are more similar to those in cyanobacteria (Synechocystis) and the heterodisulfide reductases from methanogens such as Methanocaldococcus jannaschii (formerly known as Methanococcus jannaschii) [46]. Like other gene clusters coding for E-type Frds, frdABEF contains frdE that codes for a cysteine-rich domain involved in cytochrome binding and membrane attachment [46]. The function of the protein encoded by frdF is unknown [46]. FrdA contains the conserved catalytic residues; FrdB contains motifs for binding of two iron sulfur clusters, [2Fe2S] and [4Fe4S]. The lack of [3Fe4S] may be compensated by iron sulfur clusters present in FrdE and F.

The third gene cluster with similarity to succinate:quinone oxidoreductases ( $s d h A B-1)$ lacks a gene coding for a transmembrane domain. SdhA contains the conserved catalytic residues and the SdhB contains a motif for [2Fe2S] iron sulfur cluster binding, but lacks motifs for [4Fe4S] or [3Fe4S] binding. Therefore, the required electron transfer via three iron-sulfur clusters cannot occur, meaning that sdhAB does not code for a conventional Sdh or Frd [45]. Transmembrane proton transfer may occur through cytochromes for which a variety of genes are present in the genome: $c y t c b_{561}$ (Sfum_0090-91); cytc $_{3}$ (Sfum_4047); cydAB-1 (Sfum_3008-09); cydAB2 (Sfum_0338-39); cytb5 (Sfum_3227); cytb (Sfum_2932).

The fourth gene cluster is sdhAB-2 (Sfum_2103-04). These genes are part of a larger gene cluster that contains genes predicted for aconitase (Sfum_2106), citrate synthase (Sfum_2105), fumarase (Sfum_2102) and a ubiquinone prenyl transferase (Sfum_2101). These enzymes most likely function to supply biosynthetic intermediates. A 348 bp hypothetical protein (Sfum_2100) was also detected as part of this gene cluster.

The next step is the hydroxylation of fumarate forming malate (Figure. 6). Two genes for fumarase were detected in the genome. As discussed previously, a fumarase-encoding gene (Sfum_2102) is a part of a gene cluster containing aconitase, citrate synthase, succinate dehydrogenase and ubiquinone prenyl transferase encoding genes. A second fumarase- encoding gene (Sfum_2336) does not appear to be part of a gene cluster.

Malate is oxidized to oxaloacetate by malate dehydrogenase (Sfum_0460) and oxaloacetate is decarboxylated to pyruvate by pyruvate carboxyltransferase (Sfum_0461, 0676). The decarboxylation of oxaloacetate to pyruvate is concomitant with a carboxyl transfer reaction to form methylmalonyl-CoA from propionyl-CoA (Sfum_1223). Acetyl-CoA is formed from pyruvate by pyruvate ferredoxin oxidoreductase (Sfum_279295) and the CoA moiety is recycled to activate propionate to propionyl-CoA. Acetyl-CoA could also be converted to acetyl-phosphate and acetate by phosphotransacetylase and acetate kinase encoded by Sfum_1472-73. Formation of acetate from acetylphosphate could result in ATP synthesis by substrate-level phosphorylation. However, when strain $\mathrm{MPOB}^{\mathrm{T}}$ was grown on propionate, the activity of this enzyme was below detection level, suggesting that acetate was formed exclusively via an acetyl-CoA: propionate HS-CoA transferase [22].

Taken together, the genome reveals a complete set of genes for the conversion of propionate to acetate and carbon dioxide by the methylmalonyl-CoA pathway. Also present are genes and gene clusters for electron transfer from the key carbon oxidation steps leading to hydrogen and formate formation when $S$. fumaroxidans grows syntrophically (Figure. 6). These include the previously discussed fumarate reductase for quinone reduction from succinate. Menaquinol would then, ostensibly, shuttle electrons to a membrane-bound formate dehydrogenase (carbon dioxide reductase) (Sfum_0030-1) or hydrogenase complexes (Sfum_2220-22 and Sfum_2713-16). No formate dehydrogenase genes with transmembrane helices were predicted. However, several genes coding for cytochromes were detected in the genome, which do not appear to be part of larger gene clusters. These cytochromes may provide a platform for formate dehydrogenase subunits to receive electrons from the menaquinol pool. In addition, the cytochromes may also play a role in sulfate reduction, similar to Desulfovibrio sp [47]. Reducing equivalents generated by cytosolic events, such as the oxidation of malate to oxaloacetate and pyruvate to acetyl-CoA and $\mathrm{CO}_{2}$, are probably $\mathrm{NAD}(\mathrm{P}) \mathrm{H}$ and reduced ferredoxin, respectively. Several soluble cytosolic confurcating hydrogenases (Sfum_0844-46) and formate dehydrogenases (Sfum_2703-07) probably catalyze hydrogen or formate production with the above reduced electron 
Plugge et al.

carriers in a mechanism proposed for hydrogen generation in Thermotoga maritima [48]. In this mechanism the energetically favorable production of hydrogen or formate with reduced ferredoxin pre- sumably provides the energetic input to enable the energetically unfavorable formation of hydrogen from NADH.

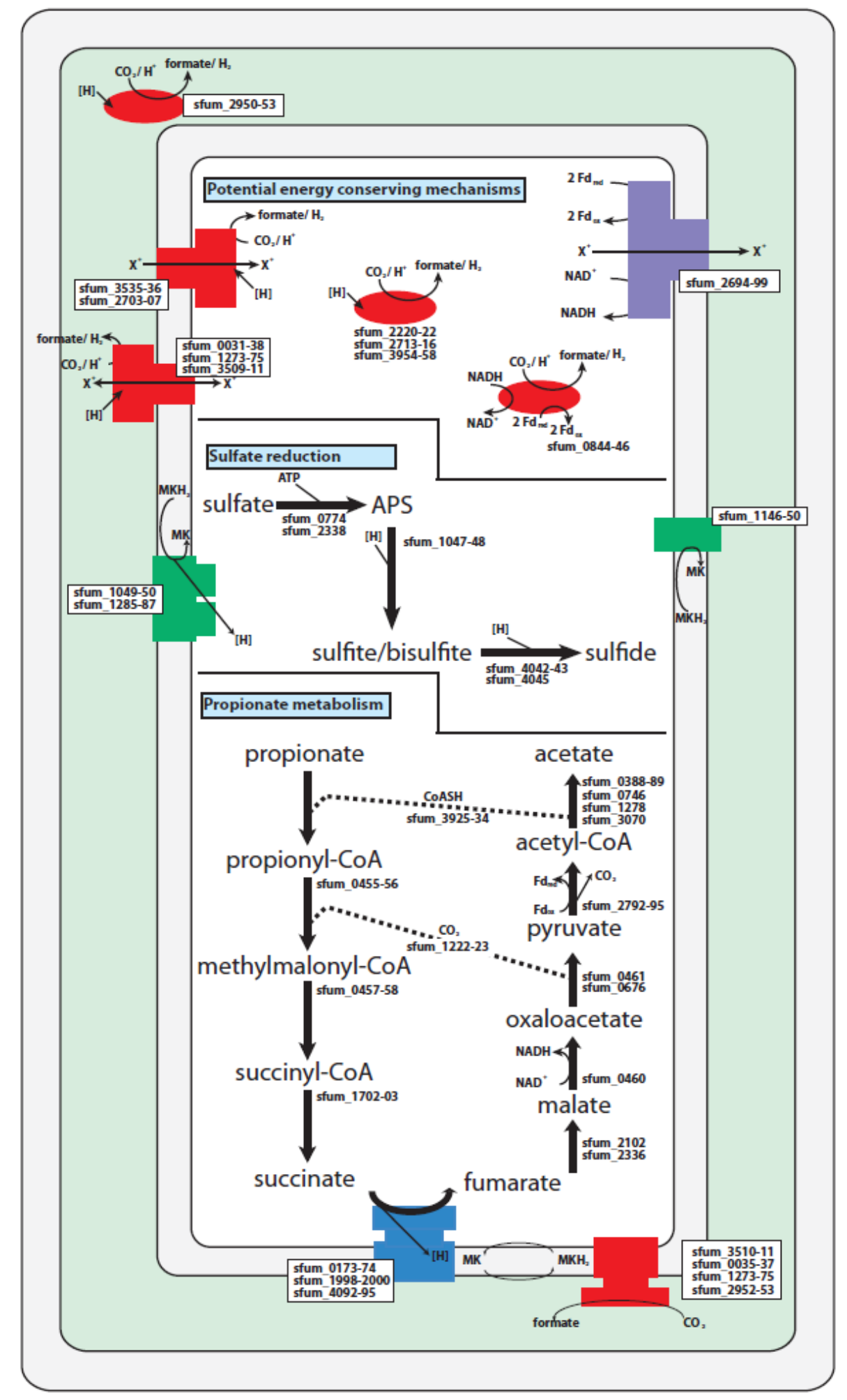

Figure 6. Metabolic reconstruction of propionate metabolism of $S$. fumaroxidans. 
Strain $\mathrm{MPOB}^{\mathrm{T}}$ ferments 7 fumarate to 6 succinate and $4 \mathrm{CO}_{2}$ in pure culture, using the acetyl-CoA cleavage pathway to oxidize fumarate to $\mathrm{CO}_{2}$ [22]. All genes encoding for the acetyl-CoA cleavage pathway are present in the genome. In this pathway, acetyl-CoA is cleaved into a methyl-group and $\mathrm{CO}$, which are both oxidized further to $\mathrm{CO}_{2}$. During propionate conversion, the pathway may be used anaplerotically to form acetyl-CoA. The genes for the acetyl-CoA pathway are scattered through the genome.

Acetyl-CoA is converted by an acetylCoA synthase/COdh complex encoded by Sfum_2564 2567 to $\mathrm{CO}_{2}$ and a methyl-group. The methyl group is further oxidized via 5,10-methylene tetrahydrofolate reductase (Sfum_3130), methylene-tetrahydrofolate dehydrogenase (S_fum 2686), methenyl-tetrahydrofolate cyclohydrolase (Sfum_1186), formyl-tetrafolate syntethase (Sfum_2687) and formate dehydrogenase to $\mathrm{CO}_{2}$. During complete oxidation of 1 fumarate to $4 \mathrm{CO}_{2}$, 6 reducing equivalents are released that are used to reduce 6 fumarate to 6 succinate.

Strain $\mathrm{MPOB}^{\mathrm{T}}$ is able to couple propionate oxidation to sulfate reduction [22]. The flow of electrons during respiratory sulfate reduction has not yet been fully described. As predicted, the genome encodes the full suite of genes necessary for dissimilatory sulfate reduction as well as several membrane complexes, which could deliver electrons from membrane electron carriers like menaquinol to cytosolic sulfate-reducing enzymes. Sulfate is first activated to adenosine-5 $\square$ phosphosulfate (APS) through the ATP dependent action of adenylylsulfate kinase. Two genes were detected that are predicted to code for adenylylsulfate kinase (Sfum_0774; 2338). Genes for APS reductase (Sfum_1047-48) were detected which likely encode the metabolic machinery necessary for the reduction of APS to sulfite and/or bisulfite. Sulfite and/or bisulfite are then reduced to sulfide by dissimilatory sulfite reductase. Alpha and beta subunits of the dissimilatory sulfite reductase were detected (Sfum_4042-43) as part of a predicted five-gene cluster along with genes that have high identity to dissimilatory sulfite reductase C (Sfum_4045). The gene organization of the alpha, beta and c-subunits of the whole cluster is different from other dissimilatory sulfate reducers [49]. Genes predicted to encode a membrane-bound dissimilatory sulfite reductase, dsrMKJOP, were detected (Sfum_1146-50) as were the three genes encoding a quinone-interacting membrane-bound oxidoreductase (Qmo) complex (Sfum_1285-87). Additionally, qmoAB genes were detected elsewhere on the chromosome as part of a larger multi-gene cluster (Sfum_1054-59) that contains genes predicted to code for a benzoylCoA reductase subunit A (Sfum_1051) and three additional hypothetical proteins of unknown function (Sfum_1052-54).

Other membrane complexes include a membranebound, ion-translocating ferredoxin:NADH oxidoreductase (Sfum_2694-99 gene product), which could drive the unfavorable formation of reduced ferredoxin from NADH by using the ion gradient, two NADH dehydrogenases (Sfum_0199209 and Sfum_1935-43), and two pyrophosphatases (Sfum_2995 and Sfum_3037).

\section{Regulation and signal transduction}

The S. fumaroxidans genome contains genes with similarity to those coding for a prototypical bacterial RNA core polymerase (RpoA, RpoB, RpoC) along with 12 sigma factors to confer promoter specificity. These sigma factors include one general housekeeping sigma 70 factor (RpoD), seven sigma 24 type stress related factors, two additional sigma 70-like factors, one FliA/WhiG sigma 28 type factor, and one 54 factor (RpoN) similar to that used for general nitrogen control in Escherichia coli. The genome also contains 31 genes with similarity to those coding for sigma 54interacting transcriptional regulators (18 with response regulator signaling domains and 7 with PAS signaling domains, and 3 with GAF signaling domains), suggesting a major role for the 54factor in global control of $S$. fumaroxidans gene expression. Numerous two-component regulatory systems (27 histidine kinase-type sensor transmitters, 11 response regulatory proteins, and 25 receiver-only domain proteins) are present in the genome. Compared to other Gramnegative microbes, $S$. fumaroxidans has a moderate number of primary transcription factors containing a helix-turn-helix motif ( 115 genes).

\section{Motility and taxis}

Unlike the thermophilic, syntrophic, propionateutilizing, Pelotomaculum thermopropionicum SI [5] from the Firmicutes, S. fumaroxidans lacks genes coding for flagellar structural proteins (i.e., basal body, motor, hook, and filament) along with the associated flagellar biogenesis, anti-28 factor (FlgM) and the E. coli type master switch proteins, 
FlhCD or CheR, CheV, and CheC proteins. However, $S$. fumaroxidans contains genes for a FliA/WhiG family RNA polymerase sigma factor, nine methylaccepting chemotaxis proteins (MCP) (three soluble and six membrane associated) with unknown roles in signal transduction plus one gene coding for each of the following signal processing proteins, CheA, CheW, CheY and CheD, and two cheB genes. Interestingly, genes for one PilQ type 4 secretion-like protein, two PilT-like retraction proteins, and PilM, PilY and PilO-like assembly proteins (one each) are predicted that may suggest alternative means of cell movement. Lastly, the absence of genes coding for pili-type nanowire proteins would suggest that direct interspecies electron transfer is unlikely [50].

\section{Host defense systems}

To explore possibilities of developing a genetic system for $S$. fumaroxidans it is crucial to investigate the mechanisms that are present in the strain that protect against foreign DNA. The genome of strain $\mathrm{MPOB}^{\mathrm{T}}$ contains two possible restrictionmodification gene clusters. The first cluster consists of three genes, of which two encode the methylase and endonuclease of a Type-II restriction-modification system (Sfum_2532 and 2533, respectively) and shows high sequence identity with PstI and BsuBI restrictionmodification systems. The third gene (Sfum_2534) encodes a modification requiring endonuclease

\section{Acknowledgements}

The European authors were financially supported by the Earth and Life Sciences division (ALW 814.02.017) and Chemical Science division (CW 700.55.343) of the Netherlands Organization for Scientific Research (NWO). CMP was supported by a short-term personal fellowship of the Netherlands Genome Initiative (NGI 050-72-408). Annotation assistance provided by Dr. McInerney's group was supported by grant DE-FG02-

\section{References}

1. Harmsen HJM, VanKuijk BLM, Plugge CM, Akkermans ADL, DeVos WM, Stams AJM. Syntrophobacter fumaroxidans sp. nov., a syntrophic propionate-degrading sulfate-reducing bacterium. Int / Syst Bacteriol 1998; 48:13831387. PubMed http://dx.doi.org/10.1099/00207713-48-4-1383

2. Mclnerney MJ, Stams AJM, Boone DR. Genus Syntrophobacter. In: Staley JT, Boone DR, Brenner DJ, de Vos P, Garrity GM, Goodfellow M, which shows high sequence identity with the $E$. coli $\mathrm{mrr}$ gene, a modification-requiring restriction enzyme. The second cluster contains, two genes encoding a putative Type-III restriction modification system (Sfum_2855 - 2856) and three genes which do not seem to be part of the restrictionmodification system. Interestingly, this system shows similarity only with hypothetical restriction-modification system coding sequences (nt-nt BLAST of both genes (endonuclease Sfum_2855 and methylase Sfum_2856): Candidatus Desulforudis audaxviator MP104C, 72\% coverage; Chlorobium limicola DSM 245, 72\% coverage; Cellvibrio japonicus Ueda107, 43\% coverage; Verminephrobacter eiseniae EF01-2, 67\% coverage). Since the genes do not show high sequence identity with described systems, it is not possible to predict the specificity of the system.

Additionally, the genome of strain $\mathrm{MPOB}^{\mathrm{T}}$ harbors genes encoding two CRISPR/Cas systems. The first system (Sfum_1345-1356) can be classified as a type I-E system associated with a 69-spacer CRISPR locus, the second (Sfum_2824-2831) as type III-A system and is associated with a CRISPR locus containing 79 spacers [51].

Taken together, strain $\mathrm{MPOB}^{\mathrm{T}}$ has multiple systems to protect itself against foreign DNA, making it a challenge to develop a genetic system for this strain.

96ER20214 from the Division of Chemical Sciences, Geosciences, and Biosciences, Office of Basic Energy Sciences of the US Department of Energy and genomic analyses provided by Dr. Gunsalus' group were supported by US Department of Energy grant DE-FG0386ER13498 and the UCLA-DOE Institute of Genomics and Proteomics.

Krieg NR, Rainey, FA, Schleifer KH (eds) Bergey's Manual of Systematic Bacteriology, second edition, vol 2 2005; Springer, NY, pp 1021-1027.

3. Boone DR, Bryant MP. Propionate-degrading bacterium, Syntrophobacter wolinii sp. nov., gen. nov., from methanogenic ecosystems. Appl Environ Microbiol 1980; 40:626-632. $\underline{\text { PubMed }}$

4. Mclnerney MJ, Struchtemeyer CG, Sieber J, Mouttaki H, Stams AJM, Schink B, Rohlin L, 
Gunsalus R. Physiology, ecology, phylogeny, and genomics of microorganisms capable of syntrophic metabolism. Ann N Y Acad Sci 2008; 1125:58-72. PubMed http://dx.doi.org/10.1196/annals.1419.005

5. Imachi H, Sekiguchi $\mathrm{Y}$, Kamagata $\mathrm{Y}$, Hanada S, Ohashi A Harada H. Pelotomaculum thermopropionicum gen. nov., sp. nov., an anaerobic, thermophilic, syntrophic propionateoxidizing bacterium. Int / Syst Evol Microbiol 2002; 52:1729-1735. PubMed http://dx.doi.org/10.1099/ijs.0.02212-0

6. Plugge CM, Balk M, Stams AJM. Desulfotomaculum thermobenzoicum subsp. thermosyntrophicum subsp. nov., a thermophilic syntrophic propionate-oxidizing spore-forming bacterium. Int J Syst Evol Microbiol 2002; 52:391399. PubMed

7. de Bok FAM, Harmsen HJM, Plugge CM, deVries MC, Akkermans ADL, de Vos WM, Stams AJM. The first true obligately syntrophic propionateoxidizing bacterium, Pelotomaculum schinkii sp. nov., co-cultured with Methanospirillum hungatei, and emended description of the genus Pelotomaculum. Int J Syst Evol Microbiol 2005;

55:1697-1703. PubMed http://dx.doi.org/10.1099/ijs.0.02880-0

8. Plugge CM, Zhang W, Scholten JCM, Stams AJM. Metabolic flexibility of sulfate-reducing bacteria. Front Microbiol 2011; 2:81. PubMed

9. Liu Y, Balkwill DL, Aldrich HC, Drake GR, Boone DR. Characterization of the anaerobic propionate-degrading syntrophs Smithella propionica gen. nov., sp. nov. and Syntrophobacter wolinii. Int J Syst Bacteriol 1999; 49:545-556. PubMed http://dx.doi.org/10.1099/00207713-49-2-545

10. De Bok FAM, Stams AJM, Dijkema C, Boone DR. Pathway of propionate oxidation by a syntrophic culture of Smithella propionica and Methanospirillum hungatei. Appl Environ Microbiol 2001; 67:1800-1804. PubMed http://dx.doi.org/10.1128/AEM.67.4.1800$\underline{1804.2001}$

11. Field D, Garrity G, Gray T, Morrison N, Selengut J, Sterk P, Tatusova T, Thomson N, Allen MJ, Angiuoli SV, et al. The minimum information about a genome sequence (MIGS) specification. Nat Biotechnol 2008; 26:541-547. PubMed http://dx.doi.org/10.1038/nbt1360

12. Woese CR, Kandler O, Wheelis ML. Towards a natural system of organisms: proposal for the domains Archaea, Bacteria, and Eucarya. Proc Natl
Acad Sci USA 1990; 87:4576-4579. PubMed http://dx.doi.org/10.1073/pnas.87.12.4576

13. Garrity GM, Bell JA, Lilburn T. Phylum XIV. Proteobacteria phyl. nov. In: Garrity GM, Brenner DJ, Krieg NR, Staley JT (eds), Bergey's Manual of Systematic Bacteriology, Second Edition, Volume 2, Part B, Springer, New York, 2005, p. 1.

14. Validation List No. 107. List of new names and new combinations previously effectively, but not validly, published. Int I Syst Evol Microbiol 2006; 56:1-6. PubMed http://dx.doi.org/10.1099/ijs.0.64188-0

15. Kuever J, Rainey FA, Widdel F. Class IV. Deltaproteobacteria class. nov. In: Garrity GM, Brenner DJ, Krieg NR, Staley JT (eds), Bergey's Manual of Systematic Bacteriology, Second Edition, Volume 2, Part C, Springer, New York, 2005, p. 922.

16. Kuever J, Rainey FA, Widdel F. Order VI. Syntrophobacterales ord. nov. In: Garrity GM, Brenner DJ, Krieg NR, Staley JT (eds), Bergey's Manual of Systematic Bacteriology, Second Edition, Volume 2, Part C, Springer, New York, 2005, p. 1021.

17. Kuever J, Rainey FA, Widdel F. Family I. Syntrophobacteraceae fam. nov. In: Garrity GM, Brenner DJ, Krieg NR, Staley JT (eds), Bergey's Manual of Systematic Bacteriology, Second Edition, Volume 2, Part C, Springer, New York, 2005, p. 1021.

18. Validation List no. 15. Validation of the publication of new names and new combinations previously effectively published outside the IJSB. Int J Syst Bacteriol 1984; 34:355-357. http://dx.doi.org/10.1099/00207713-34-3-355

19. Chen S, Liu X, Dong X. Syntrophobacter sulfatireducens sp. nov., a novel syntrophic, propionate-oxidizing bacterium isolated from UASB reactors. Int / Syst Evol Microbiol 2005; 55:13191324. PubMed http://dx.doi.org/10.1099/ijs.0.63565-0

20. Ashburner M, Ball CA, Blake JA, Botstein D, Butler $\mathrm{H}$, Cherry JM, Davis AP, Dolinski K, Dwight SS, Eppig JT, et al. Gene Ontology: tool for the unification of biology. Nat Genet 2000; 25:25-29. PubMed http://dx.doi.org/10.1038/75556

21. Plugge CM, Dijkema C, Stams AJM. Acetyl-CoA cleavage pathway in a syntrophic propionate oxidizing bacterium growing on fumarate in the absence of methanogens. FEMS Microbiol Lett 1993; 110:71-76. http://dx.doi.org/10.1111/j.15746968.1993.tb06297.x 
22. Van Kuijk BLM, Stams AJM. Sulfate reduction by a syntrophic propionate- oxidizing bacterium. Antonie van Leeuwenhoek 1995; 68:293-296. PubMed http://dx.doi.org/10.1007/BF00874139

23. Stams AJM, vanDijk JB, Dijkema C, Plugge CM. Growth of syntrophic propionate-oxidizing bacteria with fumarate in the absence of methanogenic bacteria. Appl Environ Microbiol 1993; 59:11141119. PubMed

24. Pagani I, Liolios K, Jansson J, Chen IM, Smirnova T, Nosrat B, Markowitz VM, Kyrpides NC. The Genomes OnLine Database (GOLD) v.4: status of genomic and metagenomic projects and their associated metadata. Nucleic Acids Res 2012; 40:D571-D579. PubMed http://dx.doi.org/10.1093/nar/gkr1100

25. Stams AJM, Plugge CM. Electron transfer in syntrophic communities of anaerobic bacteria and archaea. Nat Rev Microbiol 2009; 7:568-577. PubMed http://dx.doi.org/10.1038/nrmicro2166

26. Loy A, Küsel K, Lehner A, Drake HL, Wagner M. Microarray and functional gene analyses of sulfate-reducing prokaryotes in low sulfate, acidic fens reveal co-occurence of recognized genera and novel lineages. Appl Environ Microbiol 2004; 70:6998-7009. PubMed http://dx.doi.org/10.1128/AEM.70.12.6998$\underline{7009.2004}$

27. Lueders T, Pommerenke B, Friedrich MW. StableIsotope Probing of microorganisms thriving at thermodynamic limits: syntrophic propionate oxidation in flooded soil. Appl Environ Microbiol 2004; 70:5778-5786. PubMed http://dx.doi.org/10.1128/AEM.70.10.5778$\underline{5786.2004}$

28. Imachi H, Sekiguchi $Y$, Kamagata $Y$, Loy A, Qiu YL, Hugenholtz P, Kimura N, Wagner M, Ohashi A, Harada H. Non-sulfate-reducing, syntrophic bacteria affiliated with Desulfotomaculum Cluster I are widely distributed in methanogenic environments. Appl Environ Microbiol 2006; 72:20802091. PubMed http://dx.doi.org/10.1128/AEM.72.3.2080$\underline{2091.2006}$

29. Wallrabenstein C, Hauschild E, Schink B. Syntrophobacter pfennigii sp. nov., new syntrophically propionate-oxidizing anaerobe growing in pure culture with propionate and sulfate. Arch Microbiol 1995; 164:346-352. http://dx.doi.org/10.1007/BF02529981

30. Chen SY, Liu XL, Dong XZ. Syntrophobacter sulfatireducens sp. nov., a novel syntrophic, pro- pionate-oxidizing bacterium isolated from UASB reactors. Int / Syst Evol Microbiol 2005; 55:13191324. PubMed http://dx.doi.org/10.1099/ijs.0.63565-0

31. Syntrophobacter fumaroxidans taxon id. http://img.jgi.doe.gov/cgi$\underline{\text { bin } / \text { w } / \text { main.cgi?page=taxonDetail\&taxon_oid }=63}$ $\underline{9633063}$

32. DOE Joint Genome Institute. http://www.jgi.doe.gov

33. Phred/Phrap/Consed software package. http://www.phrap.org

34. Ewing B, Green P. Base-calling of automated sequencer traces using phred. II. Error probabilities. Genome Res 1998; 8:186-194. PubMed

35. Ewing B, Hillier L, Wendl MC, Green P. Basecalling of automated sequencer traces using phred. I.Accuracy assessment. Genome Res 1998; 8:175-185. PubMed

36. Gordon D, Abajian C, Green P. Consed: a graphical tool for sequence finishing. Genome Res 1998; 8:195-202. PubMed

37. Delcher AL, Harmon D, Kasif S, White O, Salzberg SL. Improved microbial gene identification with GLIMMER. Nucleic Acids Res 1999a; 27:4636-4641. PubMed http://dx.doi.org/10.1093/nar/27.23.4636

38. Delcher AL, Kasif S, Fleischmann RD, Peterson J, White O, Salzberg SL. Alignment of whole genomes. Nucleic Acids Res 1999b; 27:2369-2376. PubMed

http://dx.doi.org/10.1093/nar/27.11.2369

39. Badger JH, Olsen GJ. CRITICA: coding region identification tool invoking comparative analysis. Mol Biol Evol 1999; 16:512-524. PubMed http://dx.doi.org/10.1093/oxfordjournals.molbev.a $\underline{026133}$

40. Markowitz VM, Mavromatis K, Ivanova NN, Chen IMA, Chu K, Kyrpides NC. IMG ER: a system for microbial genome annotation expert review and curation. Bioinformatics 2009; 25:2271-2278. PubMed http://dx.doi.org/10.1093/bioinformatics/btp393

41. von Mering C, Jensen LJ, Snel B, Hooper SD, Krupp M, Foglierini M, Jouffre N, Huynen MA, Bork P. STRING: known and predicted proteinprotein associations, integrated and transferred across organisms. Nucleic Acids Res 2005; 33:D433-D437. PubMed http://dx.doi.org/10.1093/nar/gki005 
42. STRING. http://string.embl.de/.

43. Scholten JCM, Culley DE, Brockman FJ, Wu G, Zhang W. Evolution of the syntrophic interaction between Desulfovibrio vulgaris and Methanosarcina barkeri: Involvement of an ancient horizontal gene transfer. Biochem Biophys Res Commun 2007; 352:48-54. PubMed http://dx.doi.org/10.1016/j.bbrc.2006.10.164

44. Schink B. Energetics of syntrophic cooperation in methanogenic degradation. Microbiol Mol Biol Rev 1997; 61:262-280. PubMed

45. Lancaster CRD. Succinate:quinone oxidoreductases: an overview. Biochim Biophys Acta 2002; 1553:1-6. PubMed http://dx.doi.org/10.1016/S0005-2728(01)00240$\underline{7}$

46. Lemos RS, Fernandes AS, Pereira MM, Gomes CM, Teixeira M. Quinol:fumarate oxidoreductases and succinate:quinone oxidoreductases: phylogenetic relationships, metal centers and membrane attachment. Biochim Biophys Acta 2002; 1553:158-170. PubMed http://dx.doi.org/10.1016/S0005-2728(01)00239$\underline{0}$

47. Heidelberg JF, Seshadri R, Haveman SA, Hemme $\mathrm{CL}$, Paulsen IT, Kolonay JF, Eisen JA, Ward N, Methe B, Brinkac LM, et al. The genome sequence of the anaerobic, sulfate-reducing bacte- rium Desulfovibrio vulgaris Hildenborough. Nat

Biotechnol 2004; 22:554-559. PubMed http://dx.doi.org/10.1038/nbt959

48. Schut GJ, Adams MW. The iron-hydrogenase of Thermotoga maritima utilizes ferredoxin and NADH synergistically: a new perspective on anaerobic hydrogen production. I Bacteriol 2009; 191:4451-4457. PubMed http://dx.doi.org/10.1128//B.01582-08

49. Pereira IA, Ramos AR, Grein F, Marques MC, Marques da Silva M, Venceslau SS. A comparative genome analysis of energy metabolism in sulfate reducing bacteria and archaea. Front Microbiol 2011; 2:69. PubMed

50. Gorby YA, Yanina S, McLean JS, Rosso KM, Moyles D, Dohnalkova A, Beveridge TJ, Chang IS, Kim BH, Kim KS, et al. Electrically conductive bacterial nanowires produced by Shewanella oneidensis strain MR-1 and other microorganisms. Proc Natl Acad Sci USA 2006; 103:11358-11363. PubMed http://dx.doi.org/10.1073/pnas.0604517103

51. Makarova KS, Haft DH, Barrangou R, Brouns SJJ, Charpentier E, Horvath P, Moineau S, Mojica FJM, Wolf YI, Yakunin AF, et al. Evolution and classification of the CRISPR-Cas systems. Nat Microbiol Rev 2011; 9:467-477. PubMed http://dx.doi.org/10.1038/nrmicro2577 